\title{
Availability of Medicines in Community Pharmacy to Manage Patients with COVID-19 in Kenya; Pilot Study and Implications
}

Sylvia A Opanga ${ }^{1}$, Nadia Rizvi ${ }^{2}$, Annie Wamaitha ${ }^{2}$, Israel Abebrese Sefah ${ }^{3,4}$, Brian Godman ${ }^{5,6,7^{*}}$

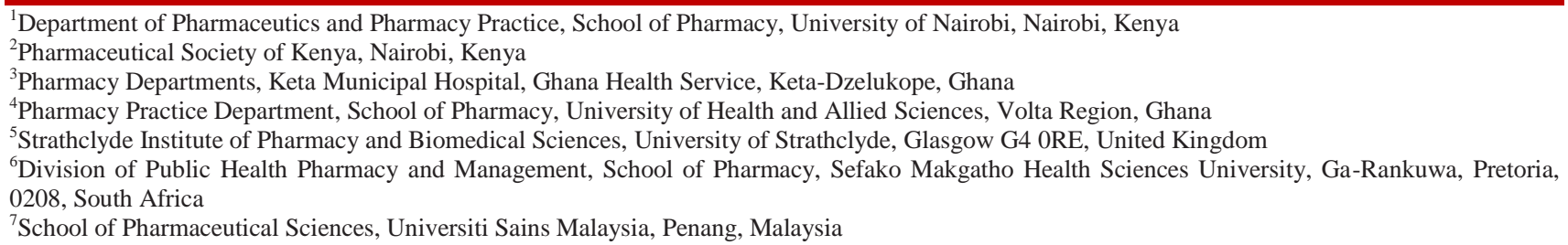

DOI: $10.36347 /$ sajp.2021.v10i03.001

| Received: 16.02.2021 | Accepted: 27.02.2021 | Published: 03.03.2021

*Corresponding author: Brian Godman

\section{Abstract}

Original Research Article

Multiple measures have been instigated across countries to prevent the spread and treat patients COVID-19 with personal protective equipment (PPE), sanitation measures and medicines. However, there has been considerable controversy surrounding initially endorsed treatments such as hydroxychloroquine with misinformation increasing prices and suicides. Prices of PPE and medicines have increased in countries following shortages, potentially catastrophic among lower- and middle-income countries (LMICs) with high co-payment levels. Consequently, there is a need to investigate changes in availability, utilisation, prices and shortages of relevant medicines during the pandemic in Kenya. To address this, a questionnaire was emailed to ten randomly selected community pharmacists from 21 purposely selected pharmacists attached to the University of Nairobi, with the survey covering the period from the start of the pandemic to the end of May 2020. This included suggestions from community pharmacists on potential ways forward with future pandemics. Six pharmacists eventually took in this pilot study. Two thirds noted increased requests for antimalarials and antibiotics; however, these were not dispensed with pharmacists recommending alternatives for symptomatic relief. There was increased use of analgesics as well as vitamins. Price rises were seen for hydroxychloroquine as well as vitamins and zinc (50-100\% increase in price); however, no shortages were seen. The pharmacists believed their future role in pandemics include education, improved stock control and patient counselling. Overall, it was encouraging to see increases in the utilisation of vitamins/ immune boosters alongside no antimalarials or antibiotics dispensed without a prescription despite the hype and requests. Community pharmacists have a key role in any pandemic with prevention and guidance, and we will be monitoring this. Countries such as Kenya can also act as exemplar countries where there continues to be high rates of selfpurchasing of antibiotics.

Keywords: COVID-19, Pharmacists, Antimalarials, Self-Purchasing, Shortages, Kenya.

Copyright $\odot 2021$ The Author(s): This is an open-access article distributed under the terms of the Creative Commons Attribution 4.0 International License (CC BY-NC 4.0) which permits unrestricted use, distribution, and reproduction in any medium for non-commercial use provided the original author and source are credited.

\section{INTRODUCTION}

Corona virus disease 2019 (COVID-19) is a disease caused by the novel corona virus, SARS COV2, first reported in Wuhan China in December 2019 [1, 2]. By 27 September 2020, there were 32.7 million confirmed cases worldwide and 991000 deaths, giving a case fatality ratio (CFR) of $3.03 \%$ [3]. This comprised 1.172 million confirmed cases and 25481 deaths in the World Health Organisation (WHO) African Region, giving a CFR of $2.17 \%$ [3]. In Kenya, since the first case was reported on 13th March 2020, by 27
September 2020 there had been 37,871 confirmed cases with a total of 689 deaths giving a CFR of $1.82 \%$ [3, 4].

Typical approaches to preventing the spread of COVID-19, and associated morbidity and mortality, have centred on social distancing, hygiene measures including wearing personal protective equipment (PPE) and hand sanitisation as well as lockdown measures including closing of borders [2,5-9]. Kenya has been no different to other African countries with its initial response to COVID-19 [8]. Preventative measures that were instigated included curfews, which were further 
extended for 30 days at the end of July 2020, combined with prohibiting the sale of alcoholic drinks and beverages in restaurants $[8,10]$. Rates of testing individuals for COVID-19 also improved to help keep track of the virus, and further preventative measures were introduced where appropriate. By 27th July 2020, a total of 268,171 cumulative tests had been undertaken in Kenya [10].

There have also been considerable economic consequences for Kenya and other African countries as a result of the pandemic and the subsequent preventative measures that were introduced to help prevent the spread of the virus, with assistance from the World Bank and others to help out [8]. This is important with potentially catastrophic consequences for families when members become ill in Kenya as a result of out-of-pocket expenditures, although there are moves towards universal healthcare in Kenya to help meet Sustainable Development Goals [11, 12].

There are also concerns across Africa including Kenya that preventative measures for infectious diseases such as malaria as well as vaccination programmes for haemophilus influenzae, measles, and rubella have been compromised by the pandemic and associated preventative measures, appreciably increasing current and future mortality rates $[8,13-15]$. Social distancing measures as well as reduction in public transport and hospital clinics also adversely affect the management of patients with noncommunicable diseases (NCDs) [8, 16]. However, there is a major role across countries for community pharmacists to help address key issues regarding both infectious diseases and NCDs as well as help control the spread of COVID-19 [17]. Community pharmacists can help with vaccination programmes as more vaccines become available and they can provide advice for protection against COVID-19 and other infectious diseases including re-enforcing hygiene and social distancing messages [13, 18-21]. In addition, address concerns with medicine supply and usage for patients with chronic NCDs as a result of lockdown activities [8, $20,22,23]$. This builds on their key role generally in ambulatory care across countries managing patients with respiratory tract infections (RTIs) as they are often the first healthcare professional patients visit with their illnesses enhanced by issues of affordability [24-27].

However, there are concerns with high rates of inappropriate self-purchasing of antibiotics across countries including African countries increasing antimicrobial resistance (AMR) rates [28-31] exacerbated by concerns with knowledge regarding antibiotics and AMR among community pharmacists [26, 32]. Encouragingly, inappropriate self-purchasing of antibiotics can be reduced though with trained pharmacists advising on alternative medicines without resorting to substantial fines which can be counterproductive especially in rural settings where pharmacists may be the only healthcare professional available [24, 33-35]. We are aware though it can be difficult in practice to differentiate RTIs from COVID19 among patients presenting with coughs and fever [36]. However, community pharmacists should encourage testing and referrals where they have concerns.

There is currently no recommended effective treatment for patients with COVID-19 apart from dexamethasone in hospitalised patients [2, 13, 37, 38]. Potential treatments including lopinavir/ritonavir and remdesivir have failed to live up to their early promise [39-41]. There was considerable hype surrounding hydroxychloroquine with or without antimicrobials despite concerns with trial designs, which resulted in shortages, price hikes and a number of suicides which have been exacerbated by endorsements from Governments and national agencies [8, 19, 42-45]. However, more recent studies have failed to show any clinical benefit from hydroxychloroquine, which has resulted in the WHO and the National Institute of Health (NIH) in the USA dropping the hydroxychloroquine arm from their studies [39,46]. Early premature recommendations are a concern not only because they raise false hope among physicians and patients but also, in the case of hydroxychloroquine and remdesivir, potentially expose patients to severe adverse drug reactions including potential cardiac sideeffects with hydroxychloroquine [45, 47, 48]. Inappropriate prescribing and dispensing of antimicrobials also enhance AMR rate, which is already a concern across Africa [25]. Alongside this, we are aware there are concerns with inappropriate use of medicinal plants to prevent and treat COVID-19 in view of their potential harm [49] as well as issues of medicine shortages across Africa enhanced by high importation rates leading to calls to increase local production [8].

As mentioned, pharmacists should play a major role in preventing and managing COVID-19, with Kenya no exception. This includes providing factual and reliable information on prevention and control strategies, ensuring a continuous supply of essential medicines, screening and referral of suspected cases, with a focus on prioritizing the care of vulnerable groups, alongside offering vaccinations when available $[8,18,42]$. We have seen the impact of misinformation on increasing sales of antimalarial medicines and antibiotics in a number of lower- and middle-income countries (LMICs) during the pandemic [19, 42,45]. Consequently, we wanted to assess the situation in Kenya especially given the catastrophic effect that illness can have on some families in Kenya; however, mindful of the fact that trained pharmacists can reduce inappropriate dispensing of antimicrobials in Kenya $[11,33]$. Consequently, we sought to assess changes in utilisation, dispensing, prices, and shortages of medicines suggested to prevent and treat COVID-19 
since the start of the pandemic. This included hydroxychloroquine and antibiotics, with the findings used to provide future guidance.

\section{METHODS}

A pre-designed questionnaire with open and closed ended questions was sent via email to ten pharmacists practicing in community pharmacists in Kenya, building on pilot studies undertaken in Ghana as well as among Asian countries [19, 42, 50]. Ten pharmacists were randomly sampled for this initial pilot study from a group of 21 community pharmacies superintended by pharmacists that are used as training sites for the University of Nairobi. They were followed up by the principal investigator (SAO) by telephone and email to complete the questionnaire to enhance response rates. The pharmacists were given a period of two weeks to respond.

The questionnaire covered the period from the start of the pandemic until the end of May 2020, and results compared with other African and Asian countries where there are opportunities for selfpurchasing of antimicrobials and family members becoming ill can have catastrophic consequences $[4,42$, 50].

The medicines of interest were antimalarials, e.g., hydroxychloroquine, antibiotics, e.g., azithromycin, and analgesics. In addition, vitamins/ immune boosters and herbal medicines use were also assessed. Pharmacists could also comment on use and shortages in other areas including personal protective equipment (PPE) and hand sanitisers if wished, with shortages seen across countries [13, 19, 42, 50]. Pharmacists were also asked to comment on substandard or falsified medications given concerns especially with hydroxychloroquine across countries following increased demand $[8,44]$.

The collected data was entered onto an excel sheet and analysed descriptively including potential ways forward. Data were typically collated into themes which required open ended questions including suggestions for the future. These answers were enhanced by the considerable experiences of the coauthors across Africa and other LMICs to provide future direction.

Ethical approval was not sought for this study as no patients were involved, with all pharmacists given the opportunity to refuse to participate. This is similar to previous studies undertaken by the co-authors in this and related areas [19, 42, 50-52].

\section{RESULTS}

\subsection{Demographics}

Only six pharmacists responded out of ten approached giving a response rate of $60 \%$ for this pilot study. Two were male and four were female, aged between 20 and 50 years (median age 32 years). Their community pharmacy work experience ranged from 2 to 15 years, with four practicing in Nairobi whilst two practiced in Mombasa city. These areas were chosen as they are currently the two most affected regions with COVID-19.

\subsection{Changes in availability and utilisation of selected medicines}

Four out of six respondents reported that there was an increase in the demand for chloroquine and hydroxychloroquine with initially the Kenyan guidelines recommending hydroxychloroquine with other medicines although acknowledging the evidence was weak. However, these antimalarials were not dispensed as they were not accompanied by a prescription.

One pharmacist reported that there was a decrease in the sale or demand for antimalarials while another reported no change. Two pharmacists noted an increase in the demand for antibiotics without a prescription and two others noted an increase specifically for azithromycin. However, no antibiotics were sold without a prescription in any of the four pharmacies. Instead, patients were educated and given different over the counter medications for the relief of their symptoms. Two pharmacists noted no change in requests or utilisation of antibiotics.

Regarding analgesics, half of the pharmacists noted increased sales of paracetamol, with one reporting an increase in panic buying, and 50\% reporting no change in the sale of analgesics. Five out of six respondents stated that they do not trade in herbal medicines so they could not report on any trends. However, the pharmacist who sells herbal medicines reported no difference in sales. All pharmacists reported an increase in the sale of vitamins C, D and Zinc. One pharmacist also voluntarily reported an increase in the sale of mouth washes.

\subsection{Price Changes}

Price changes were noted with hydroxychloroquine. Half of the pharmacists reported a $50-100 \%$ increase in the price of hydroxychloroquine over the study period. Multivitamins, particularly those containing Vitamin C, Vitamin D and Zinc, saw a 50$100 \%$ increase in prices.

Half of the pharmacists reported up to a $20 \%$ increase in the price of paracetamol, particularly the brands that were imported from the United Kingdom. The one pharmacist who sold herbal medicine did not see any price changes.

\subsection{Drug Shortages}

No drug shortages were noted during the study period except for one pharmacist who noted a shortage of ibuprofen and paracetamol brands imported from the 
UK. One pharmacist voluntarily noted there was a shortage of N95 face masks.

\subsection{Substandard/ Fake/ Spurious medication}

None of the pharmacists noted any substandard or falsified medications, which is encouraging. However, half of the respondents noted that they had detected substandard and falsified face masks.

\subsection{Roles of Community Pharmacists in Combating COVID-19}

The pharmacists also discussed possible roles to help with future pandemics and/ or reduce their impact. These are summarised in Table-1, which incorporate both short term and long-term roles.

Table-1: Role of pharmacists in future pandemics

\begin{tabular}{|c|c|}
\hline Timing & Role/ Activity \\
\hline & $\begin{array}{l}\text { - } \\
\text { - } \\
\text { - } \\
\text { Eductively undertake COVID-19 screening in pharmacies } \\
\text { posters in pharmacies to guide patients } \\
\text { - } \quad \text { Educate patients regarding procuring of suggested medicines such as hydroxychloroquine and chloroquine } \\
\text { over the counter when requested and suggest alternative approaches where necessary - especially where } \\
\text { there are concerns with self-purchasing of antimicrobials and their effectiveness/ safety in reality. As part of } \\
\text { this, educate pharmacy staff on potential approaches - including proven medicines - to prevent and manage } \\
\text { COVID-19 } \\
\text { - Ensure where possible adequate stocking of relevant medicines to help prevent shortages } \\
\text { - } \quad \text { Undertake patient counselling - especially where concerns with COVID-19 and its implications } \\
\text { Instigate safety measures in the pharmacy to help keep staff and customers safe }\end{array}$ \\
\hline & $\begin{array}{l}\text { - Continue to be an important source for information about pandemics for patients and the public. This may } \\
\text { require additional input in pharmacy schools and post qualification } \\
\text { - Continuing to demystify rumours regarding COVID-19 and other viruses through an evidenced-based } \\
\text { approach in communications with patients/ public - especially important with concerns with vaccines } \\
\text { - Clarifying the medication needed by patients and encouraging referrals where appropriate. This includes } \\
\text { resisting the need to sell antimicrobials to patients on request unless suspect patients have a bacterial } \\
\text { infection } \\
\text { - } \\
\text { Reduce the fear of COVID-19/ viruses among the public by encouraging hygienic practices and social } \\
\text { distancing - starting in pharmacies and continuing in the streets, shops and at home } \\
\text { Offer patient counselling and education - especially surrounding the unintended consequences of any } \\
\text { pandemic } \\
\text { Maintain good stock keeping practices to prevent shortages } \\
\text { Enhance the provision of care for patients with chronic diseases not able to access healthcare facilities. This } \\
\text { includes maintaining a good stock of medicines and encouraging adherence to prescribed medicines - } \\
\text { which can be particularly problematic with patients with chronic NCDs } \\
\text { Routine provision of vaccination services }\end{array}$ \\
\hline
\end{tabular}

\section{DISCUSSION}

We believe this is the first study in Kenya to assess the impact of the pandemic as well as misinformation regarding hydroxychloroquine on subsequent utilisation patterns, prices and shortages of pertinent medicines.

Encouragingly, whilst there was increased demand for antimalarials among the pharmacists in this pilot study in Kenya as a result of the pandemic, these were not dispensed. This contrasts with both Ghana and Nigeria where there was an appreciable increase in the utilisation of antimalarials, with $100 \%$ of pharmacists in the survey in Nigeria noting an increase in utilisation of at least 3-fold during the course of the pandemic [4]. There was increased utilisation of antimalarials in just under half of the pharmacists surveyed in Bangladesh during the pandemic [19]. However, this increase was more modest than seen in either Ghana or Nigeria.
Of concern were increased requests for antibiotics as a result of the pandemic. Encouragingly, these were not dispensed in the surveyed pharmacies in this pilot study, with patients educated and given over the counter medication for the relief of their symptoms, which is similar to the previous study in Kenya [33]. However, we are aware that this is not always the case in Kenya, especially among poorer communities [53].

Greater education generally of pharmacists may help to reduce inappropriate dispensing of antibiotics across LMICs given, as mentioned, concerns in their knowledge regarding AMR [26, 28, 32, 35]. This builds on suggested activities to improve future utilisation of antimicrobials outlined in Table-1.

Encouragingly as well, there were increases in the utilisation of analgesics during the study period, which is similar to a number of Asian countries [19, 42, 50]. However, there were concerns with panic buying of 
paracetamol initially among some of the surveyed pharmacies in Kenya although this is now abating. This contrasts with Ghana and Nigeria where there was no appreciable increase in their use. It was also encouraging to see increases in the utilisation of vitamins/ immune boosters among the pharmacies in Kenya, mirroring the findings in other countries [4, 42, 50].

Of concern though were increases in the prices of antimalarials in Kenya during the study period, similar to Ghana and Bangladesh [4] however, different to India, Malaysia, Pakistan and Vietnam [50]. Encouragingly though, these price increases were not as great as those seen in Nigeria [4]. Price rises were also seen for analgesics as well as vitamins/ immune boosters, which were greater than those seen among a number of African and Asian countries [4, 42, 50]. This needs to be monitored given the financial implications for families as the pandemic continues. Countries such as India can provide direction in view of their regulations regarding potential price rises in the country [42].

Encouragingly identified activities among pharmacists to improve the future management of pandemics(Table-1) including greater roles in education dispelling some of the myths, future immunisation programmes and with the management of patients with NCDs. This is similar to suggestions from other African and Asian countries to help address some of the unintended consequences of the COVID-19 pandemic $[4,8,50]$ and we will be monitoring this in the future. There are also suggestions for greater local production of medicines and other technologies among East African countries to help proactively address potential shortages as well as help reduce price hikes $[8,54]$ and again we will be monitoring this potential in the future.

We are aware that there are a number of limitations with this study including the selection process of the initial pharmacies, the limited number of pharmacists that took part in this pilot study, and the estimation of changes in utilisation and pricing patterns. However, we believe the findings are of interest and will help guide future activities of pharmacists in future pandemics in Kenya and wider.

\section{CONCLUSION}

In conclusion, we did identify increases in utilisation and prices of pertinent medicines for COVID 19 in Kenya as part of this pandemic. A number of strategies have been identified to help address concerns including the unintended consequences of the pandemic, and we will be following these up in the future.

It was encouraging that there was no dispensing of antimicrobials without a prescription, and we will continue to monitor this given ongoing concerns in Kenya including rising rates of AMR.

\section{Competing Interests and Funding}

The authors declare that they have no competing interests. There was no funding for this study.

\section{REFERENCES}

1. Wu Z, McGoogan JM. Characteristics of and important lessons from the coronavirus disease 2019 (COVID-19) outbreak in China: summary of a report of 72314 cases from the Chinese Center for Disease Control and Prevention. Jama. 2020 Apr 7;323(13):1239-42.

2. Mittal A, Chauhan T, Chauhan K. A Review on Corona Virus (Sars-Cov-2). Sch Acad J Pharm. 2020; 9(12): 330-335.

3. WHO. Coronavirus disease (COVID-19) Situation Report. 27 September 2020. Available at URL: https://www.who.int/docs/default-

source/coronaviruse/situation-reports/20200928weekly-epi-update.pdf?sfvrsn=9e354665_4.

4. Sefah IA, Ogunleye OO, Essah DO, Opanga S, Rizvi N, Wamaitha A, Guantai AN, Chikowe I, Khuluza F, Kibuule D, Nambahu L. Rapid assessment of the potential paucity and price increases for suggested medicines and protection equipment for COVID-19 across developing countries with a particular focus on Africa and the implications. Frontiers in Pharmacology. 2020 Nov 11.

5. Chu DK, Akl EA, Duda S, Solo K, Yaacoub S, Schünemann HJ, El-harakeh A, Bognanni A, Lotfi T, Loeb M, Hajizadeh A. Physical distancing, face masks, and eye protection to prevent person-toperson transmission of SARS-CoV-2 and COVID19: a systematic review and meta-analysis. The Lancet. 2020 Jun 27;395(10242):1973-87.

6. Pradhan D, Biswasroy P, Ghosh G, Rath G. A review of current interventions for COVID-19 prevention. Archives of medical research. 2020 Apr 30.

7. WHO. COVID-19 Strategic Preparedness and Response Plan - OPERATIONAL PLANNING GUIDELINES TO SUPPORT COUNTRY PREPAREDNESS AND RESPONSE. 2020. Available at https://www.who.int/docs/defaultsource/coronaviruse/covid-19-sprp-unctguidelines.pdf.

8. Ogunleye OO, Basu D, Mueller D, Sneddon J, Seaton RA, Yinka-Ogunleye AF, Wamboga J, Miljković N, Mwita JC, Rwegerera GM, Massele A. Response to the novel corona virus (COVID-19) pandemic across Africa: successes, challenges, and implications for the future. Frontiers in pharmacology. 2020 Sep 11;11:1205.

9. Reddy KP, Shebl FM, Foote JH, Harling G, Scott JA, Panella C, Fitzmaurice KP, Flanagan C, Hyle 
EP, Neilan AM, Mohareb AM. Cost-effectiveness of public health strategies for COVID-19 epidemic control in South Africa: a microsimulation modelling study. The Lancet Global Health. 2020 Nov 11.

10. Ministry of Health Kenya. COVID-19 OUTBREAK IN KENYA DAILY SITUATION REPORT - 132. 2020. Available at URL: https://www.health.go.ke/wpcontent/uploads/2020/07/Kenya-COVID-19SITREP-132-27-Jul-2020.pdf.

11. Salari P, Di Giorgio L, Ilinca S, Chuma J. The catastrophic and impoverishing effects of out-ofpocket healthcare payments in Kenya, 2018. BMJ global health. 2019 Nov 1;4(6):e001809.

12. Barasa E, Nguhiu P, McIntyre D. Measuring progress towards sustainable development goal 3.8 on universal health coverage in Kenya. BMJ global health. 2018 Jun 1;3(3).

13. Godman B. Combating COVID-19: Lessons learnt particularly among developing countries and the implications. Bangladesh Journal of Medical Science. 2020 Jul 26:S103-S108.

14. Thornton J. Covid-19: Keep essential malaria services going during pandemic, urges WHO. BMJ. 2020;369:m1637.

15. Abbas K, Procter SR, van Zandvoort K, Clark A, Funk S, Mengistu T, Hogan D, Dansereau E, Jit M, Flasche S, Houben RM. Routine childhood immunisation during the COVID-19 pandemic in Africa: a benefit-risk analysis of health benefits versus excess risk of SARS-CoV-2 infection. The Lancet Global Health. 2020 Oct 1;8(10):e1264-72.

16. Kluge $\mathrm{HH}$, Wickramasinghe $\mathrm{K}$, Rippin HL, Mendes R, Peters DH, Kontsevaya A, Breda J. Prevention and control of non-communicable diseases in the COVID-19 response. The Lancet. 2020 May 30;395(10238):1678-80.

17. Deshmukh CD, Pawar AT, Polshettiwar SA. A Global Catastrophe of Coronavirus Outbreak: History, Pathogenesis, Signs, Diagnosis and General Precautions. Sch Acad J Pharm. 2020; 9(6): 183-187.

18. Cadogan CA, Hughes CM. On the frontline against COVID-19: Community pharmacists' contribution during a public health crisis. Research in Social and Administrative Pharmacy. 2021 Jan 1;17(1):20325 .

19. Haque M, Islam S, Iqbal S, Urmi UL, Kamal ZM, Rahman A, Kamal M, Haque M, Jahan I, Islam Z, Hossain MM. Availability and price changes of potential medicines and equipment for the prevention and treatment of COVID-19 among pharmacy and drug stores in Bangladesh; findings and implications. Bangladesh Journal of Medical Science. 2020 Jul 10:36-50.

20. Elbeddini A, Prabaharan T, Almasalkhi S, Tran C. Pharmacists and COVID-19. J Pharm Policy Pract. 2020;13:36.
21. Gessler CA, Richardson RM, Hall DL, Coley KC. Operationalizing Pandemic Vaccinations at a Regional Supermarket Chain Pharmacy. Disaster Medicine and Public Health Preparedness. 2021 Feb 16:1-7.

22. Basu S. Non-communicable disease management in vulnerable patients during Covid-19. Indian J Med Ethics. 2020 Jun;5(2):103-5.

23. Sheldon TA, Wright J. Twin epidemics of covid-19 and non-communicable disease. BMJ. 2020;369:2618.

24. Marković-Peković V, Grubiša N, Burger J, Bojanić L, Godman B. Initiatives to reduce nonprescription sales and dispensing of antibiotics: findings and implications. Journal of research in pharmacy practice. 2017 Apr;6(2):120.

25. Godman, B., Haque, M., McKimm, J., Abu Bakar, M., Sneddon, J., Wale, J., Campbell, S., Martin, A.P., Hoxha, I., Abilova, V. and Anand Paramadhas, B.D., 2020. Ongoing strategies to improve the management of upper respiratory tract infections and reduce inappropriate antibiotic use particularly among lower and middle-income countries: findings and implications for the future. Current medical research and opinion, 36(2), pp.301-327.

26. Saleem Z, Hassali MA, Hashmi FK, Godman B, Saleem F. Antimicrobial dispensing practices and determinants of antimicrobial resistance: a qualitative study among community pharmacists in Pakistan. Family medicine and community health. 2019;7(3).

27. Bilal M, Haseeb A, Khan MH, Arshad MH, Ladak AA, Niazi SK, Musharraf MD, Manji AA. Selfmedication with antibiotics among people dwelling in rural areas of Sindh. Journal of clinical and diagnostic research: JCDR. 2016 May;10(5):OC08OC13.

28. Kalungia A, Godman B. Implications of nonprescription antibiotic sales in China. Lancet Infectious Diseases. 2019 Dec 31;19(12):1272-3.

29. Sakeena MH, Bennett AA, McLachlan AJ. Nonprescription sales of antimicrobial agents at community pharmacies in developing countries: a systematic review. International journal of antimicrobial agents. 2018 Dec 1;52(6):771-82.

30. Kalungia AC, Burger J, Godman B, Costa JD, Simuwelu C. Non-prescription sale and dispensing of antibiotics in community pharmacies in Zambia. Expert review of anti-infective therapy. 2016 Dec 1;14(12):1215-23.

31. Kibuule D, Kagoya HR, Godman B. Antibiotic use in acute respiratory infections in under-fives in Uganda: findings and implications. Expert review of anti-infective therapy. 2016 Sep 1;14(9):863-72.

32. Hoxha I, Malaj A, Kraja B, Bino S, Oluka M, Marković-Peković V, Godman B. Are pharmacists' good knowledge and awareness on antibiotics taken for granted? The situation in Albania and future implications across countries. Journal of 
Sylvia A Opanga et al., Sch Acad J Pharm, Mar, 2021; 10(3): 36-42

global antimicrobial resistance. 2018 Jun 1;13:2405 .

33. Mukokinya MM, Opanga S, Oluka M, Godman B. Dispensing of antimicrobials in Kenya: A crosssectional pilot study and its implications. Journal of research in pharmacy practice. $2018 \mathrm{Apr} ; 7(2): 77$.

34. Chowdhury M, Stewart Williams J, Wertheim H, Khan WA, Matin A, Kinsman J. Rural community perceptions of antibiotic access and understanding of antimicrobial resistance: qualitative evidence from the Health and Demographic Surveillance System site in Matlab, Bangladesh. Glob Health Action. 2019;12(sup1):1824383.

35. Chang J, Xu S, Zhu S, Li Z, Yu J, Zhang Y, Zu J, Fang Y, Ross-Degnan D. Assessment of nonprescription antibiotic dispensing at community pharmacies in China with simulated clients: a mixed cross-sectional and longitudinal study. The Lancet Infectious Diseases. 2019 Dec $1 ; 19(12): 1345-54$.

36. Ongole JJ, Rossouw TM, Fourie PB, Stoltz AC, Hugo J, Marcus TS. Sustaining essential healthcare in Africa during the COVID19 pandemic. Int $\mathrm{J}$ Tuberc Lung Dis. 2020 Jun 1;24(6):643-5.

37. Horby P, Lim WS, Emberson JR, Mafham M, Bell JL, Linsell L, et al. Dexamethasone in Hospitalized Patients with Covid-19 - Preliminary Report. N Engl J Med. 2020.

38. Sterne JA, Murthy S, Diaz JV, Slutsky AS, Villar J, Angus DC, Annane D, Azevedo LC, Berwanger O, Cavalcanti AB, Dequin PF. Association between administration of systemic corticosteroids and mortality among critically ill patients with COVID19: a meta-analysis. Jama. 2020 Oct 6;324(13):1330-41.

39. WHO. WHO discontinues hydroxychloroquine and lopinavir/ritonavir treatment arms for COVID-19. 4 July 2020. Available at URL: https://www.who.int/news-room/detail/04-072020-who-discontinues-hydroxychloroquine-andlopinavir-ritonavir-treatment-arms-for-covid-19.

40. Dyer O. Covid-19: Remdesivir has little or no impact on survival, WHO trial shows. BMJ. 2020;371:m4057.

41. Pan H, Peto R, Henao-Restrepo A-M, Preziosi MP, Sathiyamoorthy V, et al. Repurposed Antiviral Drugs for Covid-19 - Interim WHO Solidarity Trial Results. The New England journal of medicine. 2020:NEJMoa2023184.

42. HAQUE M, Kumar S, Charan J, Bhatt R, Islam S, Dutta S, Abhayanand JP, Sharma Y, Sefah IA, Kurdi A, Wale J. Utilisation, availability and price changes of medicines and protection equipment for COVID-19 in India: findings and implications Short title: COVID-19 and price changes of treatments in India. Frontiers in Pharmacology. 2020;11:1822.

43. International Society of Antimicrobial Chemotherapy. Official Statement from International Society of Antimicrobial
Chemotherapy (ISAC) - Hydroxychloroquine and azithromycin as a treatment of COVID-19: results of an open-label non-randomized clinical trial (Gautret P et al. PMID 32205204). Available at URL: $\quad$ https://www.isac.world/news-andpublications/official-isac-statement.

44. Abena PM, Decloedt EH, Bottieau E, Suleman F, Adejumo P, Sam-Agudu NA, TamFum JJ, Seydi M, Eholie SP, Mills EJ, Kallay O. Chloroquine and hydroxychloroquine for the prevention or treatment of COVID-19 in Africa: caution for inappropriate off-label use in healthcare settings. The American journal of tropical medicine and hygiene. 2020 Jun 3;102(6):1184-8.

45. Das S, Bhowmick S, Tiwari S, Sen S. An updated systematic review of the therapeutic role of hydroxychloroquine in coronavirus disease-19 (COVID-19). Clinical drug investigation. 2020 Jul;40:591-601.

46. NIH. NIH halts clinical trial of hydroxychloroquine. 20 June 2020. Available at URL: https://www.nhlbi.nih.gov/news/2020/nihhalts-clinical-trial-hydroxychloroquine.

47. Charan J, Kaur RJ, Bhardwaj P, Haque M, Sharma P, Misra S, Godman B. Rapid review of suspected adverse drug events due to remdesivir in the WHO database; findings and implications. Expert review of clinical pharmacology. 2020 Dec 30:1-9.

48. Ferner RE, Aronson JK. Chloroquine and hydroxychloroquine in covid-19.

49. Yang Y. Use of herbal drugs to treat COVID-19 should be with caution. The Lancet. 2020 May 30;395(10238):1689-90.

50. Godman B, Haque M, Islam S, Iqbal S, Urmi UL, Kamal ZM, Shuvo SA, Rahman A, Kamal M, Haque M, Jahan I. Rapid assessment of price instability and paucity of medicines and protection for COVID-19 across Asia: findings and public health implications for the future. Frontiers in public health. 2020;8.

51. Miljković N, Godman B, Kovačević M, Polidori P, Tzimis L, Hoppe-Tichy T, Saar M, Antofie I, Horvath L, De Rijdt T, Vida RG. Prospective risk assessment of medicine shortages in Europe and Israel: findings and implications. Frontiers in pharmacology. 2020 Mar 26;11:357.

52. Gad M, Salem A, Oortwijn W, Hill R, Godman B. Mapping of current obstacles for rationalizing use of medicines (CORUM) in Europe: current situation and potential solutions. Frontiers in pharmacology. 2020 Mar 3;11:144.

53. Jacobs A, Richtel M. In a Poor Kenyan Community, Cheap Antibiotics Fuel Deadly DrugResistant Infections. New York Times. 2019. Available at URL: https://www.nytimes.com/2019/04/07/health/antibi otic-resistance-kenya-drugs.html.

54. EAC Secretariat. East African Community COVID-19 Response Plan. 2020. Available at URL: https://www.eac.int/coronavirus. 
